\title{
Correction to: Habitat suitability modeling for the endangered Bengal slow loris (Nycticebus bengalensis) in the Indo-Chinese subregion of India: a case study from southern Assam (India)
}

\author{
Amir Sohail Choudhury ${ }^{1} \cdot$ Parthankar Choudhury ${ }^{1} \cdot$ Rejoice Gassah ${ }^{2}$
}

Published online: 7 February 2022

(c) The Author(s), under exclusive licence to Japan Monkey Centre 2022

\section{Correction to: Primates https://doi.org/10.1007/s10329-021-00967-x}

The following errors were corrected by this correction.

1. In the original publication of the article, all the units in the third sentence of the caption of the Fig. 2 should be 'acres', and read as ' $[1=$ Patch forest; $2=$ Edge; $3=$ Perforated; $4=$ Core forest $\mathrm{I}(<250$ acres $) ; 5=$ Core forest II (250-500 acres); $6=$ Core forest III ( $>500$ acres); $7=$ Non-forest]"

2. In the original publication of the article, the Supplementary material 3 should be the following.

The original article can be found online at https://doi.org/10.1007/ s10329-021-00967-x.

Parthankar Choudhury

parthankar@rediffmail.com

1 Wildlife Conservation and Research Laboratory, Department of Ecology and Environmental Science, Assam University, Silchar, Assam 788011, India

2 Makunda Christian Hospital, Karimganj, Assam 788727, India 

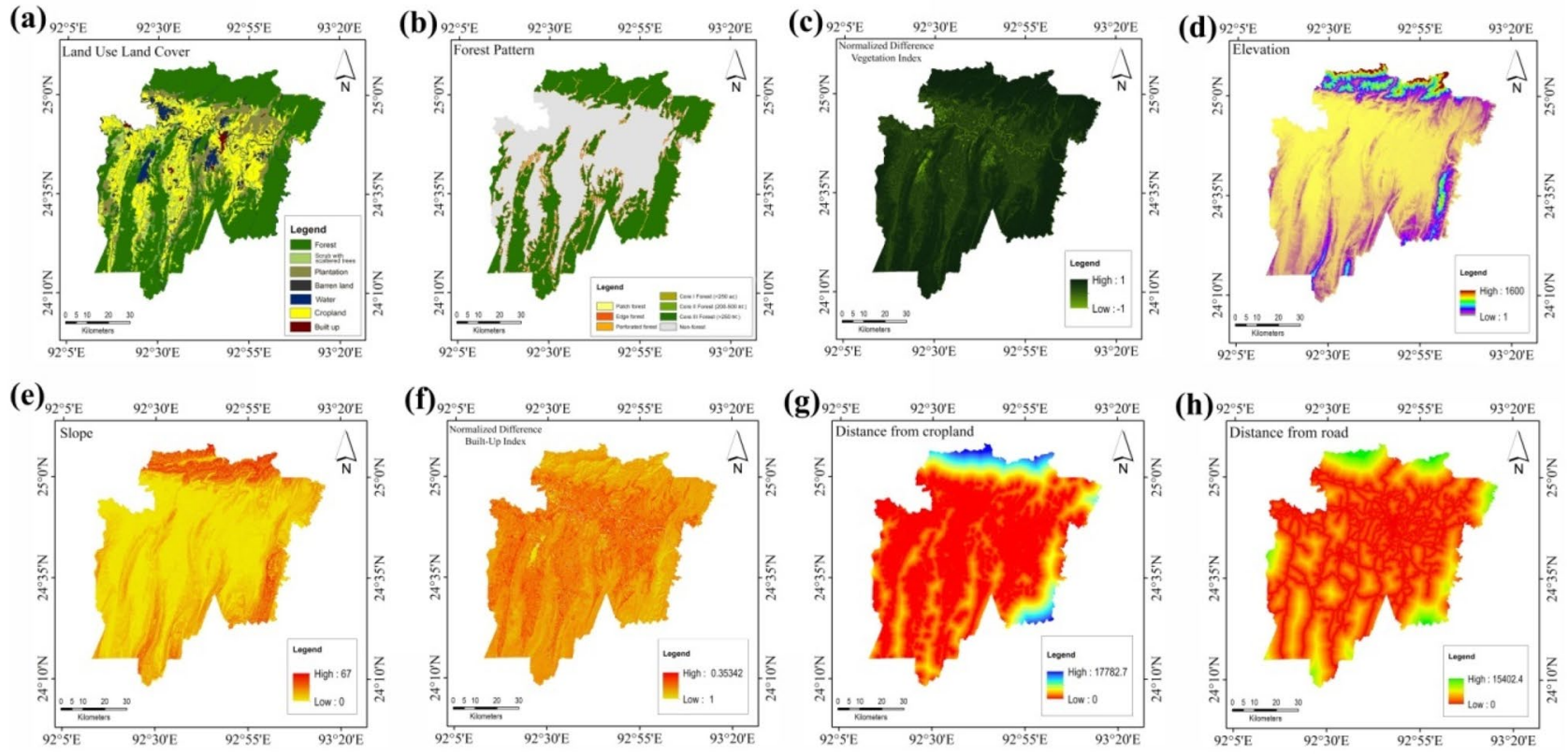

The high-resolution image of the corrected supplemental material of the same is attached herewith.

3. In the original publication of the article, the caption of the Supplementary material 3 should be read as "Models of biophysical factors - (a) Land Use Land Cover of study area; (b) Forest pattern (ac=acres); (c) Normalized difference vegetation index; (d) Elevation (in meters); (e) Slopes (in \%); (f) Normalized difference built up index; (g) Distance from croplands (in meters);

and (h) Distance from road (in meters). These models were generated using ArcGis software."

Publisher's Note Springer Nature remains neutral with regard to jurisdictional claims in published maps and institutional affiliations. 